\title{
Amoeba: The New Generation of Self-Managing Human Systems
}

While the General Motors Co. struggles with fifteen to eighteen levels of the management hierarchy, most Japanese companies now work with only five to six. But the Lincoln Electric Co. of Cleveland, Ohio, has only two such levels. The Kyocera Co. of Kyoto, Japan, has none, due to the organizational innovation: the amoeba system.

Traditional management hierarchies are thus crumbling down and even disappearing: radically, rapidly and irreversibly. Anybody who has lived through the horrors of the bureaucratic hierarchy of command socialism can only shout: Free at last!

Still, some continue to propagate the nostalgia for layers upon layers of accountability, for singleminded "getting things done", for the leisurely time span of boss's authority and "command of the troops." [1] In spite of the HBR (Harvard Business Review) noble efforts, hierarchies are being eaten up by the amoebas.

Amoeba has been used as a metaphor for the new management philosophy based on autonomy, flexibility and self-management of employees [2]. Amoebas are individual cells moving around in search of bacteria to eat. Often they eat so much and reproduce so rapidly that they deplete their food supply. In such cases of food scarcity they move rapidly to a central point, collecting themselves in a well differentiated aggregation assuming a shape of a "slug".

This "slug", with head and tail, moves through the environment in collective search for new food sources. Changing of the roles of individual amoebas is required: the original leaders who formed the center of attraction have been dispersed throughout the "slug", and new leaders emerged, forming the searching head.

Once the leaders located the new source of food, they change quickly from the first to the last:

\section{IOS Press}

Human Systems Management 9 (1990) 57-59 they form a base of a stalk which follower-amoebas continue to build up into a mushroom-like metaorganism. At its top, hundreds of thousands of amoebas turn into small dry spores and, after the mushroom "head" bursts, disperse to new nourishing environments. When they fall to earth, they change once again into the individual amoebas which reproduce through cellular division. This ecological cycle is repeated.

This amoeba metaphor has now found its practical organizational embodiment in the amoeba system at Kyocera Corporation [3]. This system is very much reminiscent of the famous Bat'a-system in Moravia of the 20 s and 30 s. It is with a special sense of joy and satisfaction that during my 1990 visit in Moravia, I have found the amoeba systems very much alive and eating up the hierarchies in the DAK Slušovice, JZD Práče and its beginnings in JZD Třinec. Employees owning the means of production, from trucks and machines, through beds of commercial carnations, to flocks of chicken and herds of cattle. Employees contracting their services and products to other such employees-owners under system of intracompany prices, accounting and profit sharing.

At Kyocera, the "amoebas" are independent, profit sharing and self-responsible units of three to fifty employees. Each amoeba carries out its own statistical control, profit system, cost accounting and personnel management. They compete, subcontract and cooperate among themselves on the basis of the intracompany market of transfer prices.

Depending on the demand and amount of work, amoebas can divide into smaller units, move from one section of the factory to another, or integrate with other amoebas or departments. All amoebas are continually on the lookout for a better buyer for their intermediate products. Many amoebas even produce the same or similar products. They are authorized, as in the Bat'a-system, to trade intermediate products with outside companies: if the in- 
ternal vendor is unreasonable, the buyer amoeba will search for a satisfactory supplier outside Kyocera.

A most remarkable feature towards autonomy is the member trading: Heads of amoebas lend and borrow members and so eliminate losses caused by surplus labor. So, Kyocera's amoebas multiply, disband and form new units in the spirit of autopoiesis (self-production) of the enterprise. Amoeba division and breakup are everyday occurrences and are based on the criteria of output and worker's added value per hour.

This concept of ultimate flexibility is best summed up by Kyocera's President Inamori: “Development is the continued repetition of construction and destruction;' as if coming directly from the systems theories of autopoietic self-organization.

Neither age nor training are essential to become the head of an amoeba: only the faculty for the job under the immediate circumstances. If unsuitable, amoeba heads are being replaced immediately.

This system represents quite a revolutionary step beyond the traditional Toyota "just-in-time" system: at Kyocera, orders received by the sales department are passed directly to the amoeba of the final process. The rest of the amoebas in the preceding processes are given free rein: the intracompany market takes over. Kyocera Corporation is one of the most profitable companies in Japan.

It is quite obvious that modelling of such "biological" organizations cannot be carried out through systems of linear or nonlinear equations. Entirely new principles are needed and amoeba ecosystems do have one thing in common: they are autopoietic, i.e. selfproducing. In addition to the fact that they produce something else, they also continually produce themselves. In that sense they are close to biological systems and must be based on the following minimal production rules:

1) production (poiesis): the rules and regulations guiding the entry of new living components (such as birth, membership, acceptance);

2) bonding (linkage): the rules guiding associations, functions and positions of individuals during their tenure within organization;

3) degradation (disintegration): processes associated with the termination of membership (death, separation, expulsion).

The above three poietic (production) processes can be interconnected into autopoietic cycle of selfproduction. All such circularly concatenated processes represent "productions" of components necessary for other processes, not only the one designated Production. To emphasize this crucial point we speak of poiesis instead of production and autopoiesis instead of self-production [4]. Although in reality hundreds of processes can be so interconnected, the above three-process model represents the minimum conditions necessary for autopoiesis to emerge.

Any viable business enterprise is also engaged in two types of production: production of something else than itself (product, service), and production of itself (regeneration of the process, skills and knowledge). The matrix of organizational knowledge, the true capital that moves and drives all other forms of capital, has to be continually renewed, regenerated and reproduced.

It is interesting to note that so far all economics and all management have been concerned only and exclusively with producing something else, not with self-production of the enterprise. This incredible neglect of the most important business function is probably due to dominance of labor and technology over knowledge until the second half of the twentieth century. As modern enterprise discovers the role of knowledge as capital, its reproduction becomes vital. For modern enterprise it is not as important what is produced but that it is produced and how. Regeneration of competitive productive capacity is more important than the immediate flexible decision as to what exactly is it going to be applied to.

The self-production of the enterprise is swiftly coming to focus of intelligent managers and businessmen. Also in Human Systems Management we are preparing for the fall 1990 a special issue where the notions of institutional autopoiesis become explicit concerns. Titles like "The identity maintenance in companies", "Synergetics and chaos in companies", "Boundary management" or "Structural properties of ambiguity in organizations", are good indicators that the new age of management has arrived.

What may sound like a sci-fi or an extravagant 
experiment to some, is a pragmatic and no-nonsense way to profits, quality and employee/customer satisfaction to others. The absolute flexibility of the amoebas is not extravagant but necessary and natural culmination of the decades of searching for knowledge vested in the employee.

The metaphors and practice of the amoebas lead directly to the notion of business ecosystem. Natural ecosystems are made up of a very large number of parts and many different kinds of each part: the workings of ecosystems must result from the action of their individual parts, not from the imposed will of any particular part.

A good example of emerging business ecosystem is the Omron Tateisi Electronics evolved holonic enterprise in which the separate divisions or functions are synergetically integrated and operated: diversification loses it meaning without a context of integration [5].

Omron has also introduced the Neo-Producer (Neo-P) System, designed to consult the local community from the start and invite its capital participation, so that some of the dividends could go directly to the local area. This perception of Omron as a local company yields the benefits of local cooperation and conciliation.

As completely independent companies, the Neo$P$ factories have virtual autonomy in everything from corporate finance to personnel and wages. They are also free to invite employees to become company shareholders.

In the rural areas of Japan, Omron has also realized the old Henry Ford dream of a direct and true farm-factory partnership. The benefits to both sides are too numerous to list here. Mr. Tateisi simply comments that "the local agricultural coopera- tion is a charming way of doing business.'

It is quite gratifying to see that the integration of agricultural and industrial production has achieved such high levels in mentioned Moravian cooperatives, where one finds top herds of cattle and worldclass corn being tended by employees of the same company that also produces computers, plastic containers and agricultural machinery, among other things.

Whether in Japan, or in Moravia, or in the U.S.A., the age of the amoeba has arrived.

\section{References}

[1] See for example Elliott Jaques, "In Praise of Hierarchy," Harvard Business Review, Jan.-Feb. 1990, pp. 127-133.

[2] See M. Zeleny, R. Cornet and J.A.F. Stoner, Moving from the Age of Specialization to the Era of Integration, Fordham University GBA Working Paper 89-103-8, New York, 1989.

[3] See K. Hamada and Y. Monden, "Profit Management at Kyocera Corporation: The Amoeba System." In: Japanese Management Accounting, edited by Y. Monden and M. Sakurai, Productivity Press, Cambridge, MA, 1989, pp. 197-210.

[4] Von Hayek is explicitly listing autopoiesis, cybernetics, spontaneous order, synergetics and systems theory as being directly applicable to the extended social orders. See F.A. Hayek, The Fatal Conceit: The Errors of Socialism, University of Chicago Press, Chicago, 1988, p. 8.

[5] Kazuma Tateisi, The Eternal Venture Spirit, Productivity Press, Cambridge, MA, 1989, pp. 170-171.

Milan ZELENY Graduate School of Business Fordham University at Lincoln Center New York, NY 10023 U.S.A. 